\title{
HINDUSTANI WORKERS ON THE PACIFIC COAST
}

\author{
By \\ Rajani Kanta Das, M. Sc., Ph. D. \\ Lecturer in Economics, New York University \\ Former Special Agent, Department of Labor, \\ United States Government.
}

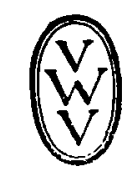

1923

WALTER DE GRUYTER Q Co. VORMALS G. J. GOSCHEN'SCHE VERLAGSHANDLUNG J. GUTTENTAG, VERLAGSBUCHHANDLUNG - GEORG REIMER - KARL J. TRÜBNER - VEIT \& COMP. "/ BERLIN and LEIPZIG " 